\title{
REVIEW
}

\section{Profile of men's health in Malaysia: problems and challenges}

\author{
Seng Fah Tong ${ }^{1,2}$, Wah Yun Low ${ }^{3}$ and Chirk Jenn $\mathrm{Ng}^{4}$
}

Men's health concerns have evolved from the traditional andrology and male sexual health to a more holistic approach that encompasses male psychological, social and physical health. The poor state of health in men compared to their female counterparts is well documented. A review of the epidemiological data from Malaysia noted a similar trend in which men die at higher rates in under 1 and above 15 years old groups and most disease categories compared to women. In Malaysia, the main causes of death in men are non-communicable diseases and injuries. Risk factors, such as risk-taking behaviour, smoking and hypertension, are prevalent and amenable to early interventions. Erectile dysfunction, premature ejaculation and prostate disorders are also prevalent. However, many of these morbidities go unreported and are not diagnosed early; therefore, opportunities for early intervention are missed. This reflects poor health knowledge and inadequate health-care utilisation among Malaysian men. Their health-seeking behaviour has been shown to be strongly influenced by family members and friends. However, more research is needed to identify men's unmet health-care needs and to develop optimal strategies for addressing them. Because the Malaysian population is aging and there is an increase in sedentary lifestyles, optimizing men's health will remain a challenge unless effective measures are implemented. The existing male-unfriendly health-care system and the negative influence of masculinity on men's health behaviour must be addressed. A national men's health policy based on a male-friendly approach to health-care delivery is urgently needed to provide a framework for addressing these challenges.

Asian Journal of Andrology (2011) 13, 526-533; doi:10.1038/aja.2010.125; published online 28 February 2011

Keywords: aging male; cause of death; epidemiology; health promotion; Malaysia; men's health; non-communicable diseases; risk factors

\section{INTRODUCTION}

Men's health has been recognized as a significant health issue in the world since the late twentieth century. ${ }^{1,2}$ Increasingly, men's health has evolved to encompass their psychological and social well-being in addition to sexual and urological health. The trigger of such changes is the acknowledgement of the discrepancy in life expectancy between men and women. The life expectancy for men at birth is shorter than that for women by an average of 4 to 6 years in almost every country in the world. ${ }^{3,4}$ It has also been documented that the differences in life expectancy are unlikely to be due solely to the biological differences between the sexes but are largely a result of the complex interaction between men and their sociocultural influences. ${ }^{5-7}$ Many of the causes of death in men are attributed to their lifestyles and unhealthful behaviour, such as risk-taking behaviour, poor health-care utilisation, smoking, alcohol and obesity. ${ }^{7,8}$ On the other hand, sexual health is also gaining attention due to its impact on men's quality of life ${ }^{9}$ and close links to cardiovascular risk factors. ${ }^{10,11}$ Although much of the knowledge about men's health and the causes of men's health problems is derived from studies conducted in developed countries in the West, there is increasing interest in men's health in East Asian countries, and a few multinational studies on men's health-seeking behaviour have been successfully conducted. ${ }^{12-14}$ However, most men's health research in Asian countries is disease oriented, and Malaysia is no exception.

In Malaysia, the life expectancy for men at birth is 71.7 years compared to 76.5 years for women. ${ }^{15}$ Healthy life expectancy, which is defined as the period of life without significant disability, is 62 years for men compared to 66 years for women. ${ }^{4}$ The overall health status of Malaysians, in particular women and children, has improved substantially over the last 50 years. ${ }^{16}$ However, the gap in life expectancy between men and women remains. ${ }^{4}$ Men do not inherently have a shorter life expectancy. ${ }^{6}$ Therefore, men's health is a pertinent issue in Malaysia, and effective measures are needed to improve their health status. Research and measures to improve the health status of men are lacking and are not gender streamlined. ${ }^{17}$ This paper aims to review the mortality and morbidity patterns of men in Malaysia. It will also identify research gaps and highlight potential challenges faced in the improvement of men's health in Malaysia.

\section{MATERIALS AND METHODS}

The main sources of data used in this review included reports from the Malaysian National and Health Morbidity Study (NHMS) III of 2006, 
the Malaysia Department of Statistics, the Malaysian Burden of Disease and Injury Study 2004, and the World Health Statistics 2009 (WHO). The NHMS is a national survey that has been conducted every 10 years since 1986 . The participants were randomly selected from the enumeration blocks of living quarters compiled by the government of Malaysia. ${ }^{18}$ In the NHMS, adults were defined as $\geqslant 18$ years old. We extracted information on the conditions that cause significant disease burden in Malaysia, such as cardiovascular disease and its risk factors, infection, cancer, psychological morbidities and injuries. We supplemented the findings with published epidemiological data relevant to men's health. The relevant electronic databases (Medline, Scopus and ISI web of Science) were searched using the main keywords related to men's health in Malaysia: prostate, lower urinary tract symptoms (LUTS), male sexual health, erectile dysfunction (ED), cardiovascular risk, alcohol, smoking, exercise and obesity. The full list of search terms is available from the author. We included all publications in the last 15 years that reported on the epidemiological data of interest. Due to the heterogeneity of the methods and the reporting used in the studies, we could only provide a narrative summary of the findings. In addition to reporting the prevalence and incidence rates of the disorders, the disability-adjusted life years (DALYs) are also presented to indicate the disease burden. DALY takes into account the fatal and non-fatal outcomes, which therefore makes the comparison of the burden of diseases with different mortality rates possible. One DALY is equivalent to one lost year of healthy life due to premature death or disability. ${ }^{19}$

\section{RESULTS}

\section{Mortality rate and causes of death in Malaysian men}

The adult mortality rate reported by WHO in 2007 for men aged 15-60 years was almost double that of women (Figure 1). Compared to the data in 1990 and 2000, the decline in mortality rate for females was 30 per 1000 population since 1990 compared to only 25 per 1000 for males. ${ }^{4}$ Local published data from the Department of Statistics of Malaysia also showed that the number of deaths in men was higher in under 1 and above 15 years old groups compared to women (Figure 2). ${ }^{20}$ With the overall improvement in socioeconomic status

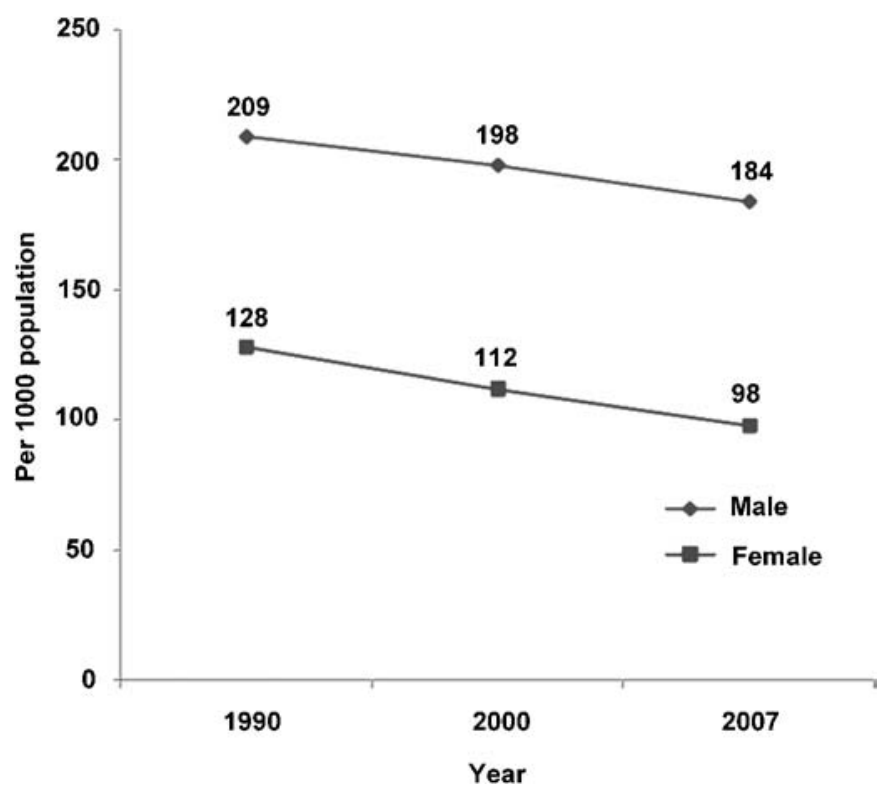

Figure 1 Adult mortality rates in Malaysia from 1997 to $2007 .{ }^{4}$

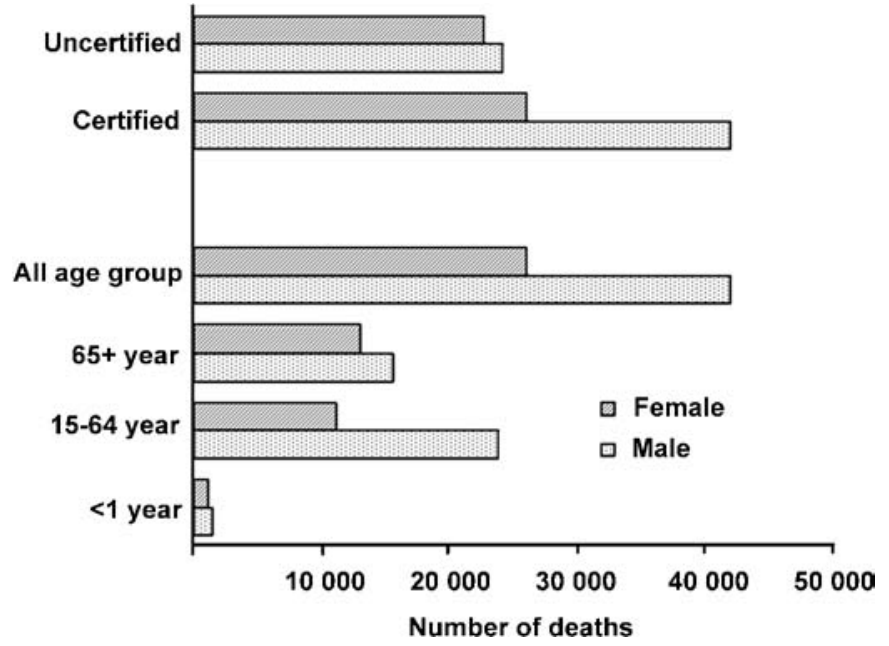

Figure 2 Total number of deaths in Malaysia in 2006. ${ }^{20}$

in Malaysia since independence in 1957, the major causes of death in Malaysia have shifted from communicable diseases to chronic non-communicable diseases, such as cardiovascular disease. ${ }^{16}$ Hypertension was noted to be an important health risk as early as $1975 .^{21}$ At that time, communicable diseases contributed to $28 \%$ of years of life lost compared to $55 \%$ from non-communicable diseases and $17 \%$ from injuries. ${ }^{4}$ In 2006 , the most common causes of death in men were as follows: ischaemic heart disease, which constituted $13.3 \%$ of total certified death; motor vehicle accidents (7.9\%); septicaemia (6.3\%); cerebrovascular disease $(6.3 \%)$; and pneumonia $(5.2 \%) .{ }^{20}$ Cancer was the seventh most common cause of medically certified death and the third most common cause of non-medically certified death in Malaysia. ${ }^{20}$ In 2000, tracheal, bronchial and lung cancers were the ninth most common cause of death in men, whereas breast cancer was the eighth most common cause of death in women. ${ }^{22}$

\section{Cardiovascular risk factors}

According to the Malaysian Burden of Disease and Injuries Study 2000, the disease accounting for the largest share of disease burden in men was cardiovascular disease, which contributed to $20 \%$ of the total DALYs in men. ${ }^{22}$ Therefore, modifiable cardiovascular risk factors are among the most important morbidities in men. The prevalence of modifiable cardiovascular risk factors in men has escalated since the first NHMS in 1986. In addition to lifestyle risks, hypertension was found to be the most prevalent modifiable risk factor among men aged 18 years and older $(33.2 \%)$ in the NHMS III $2006 .{ }^{23}$ This was followed by hypercholesterolaemia, defined by a fasting total serum cholesterol of $\geqslant 5.2 \mathrm{mmol}^{-1}(18.6 \%)$ and diabetes (11.9\%). Among men who were diagnosed with hypertension and hypercholesterolaemia, only 31.5 and $21.3 \%$, respectively, were aware of their condition. Of the $11.9 \%$ of men who were diagnosed with diabetes, up to $5.1 \%$ were newly diagnosed at the time of the survey based on a modified glucose tolerance test. Impaired glucose tolerance (IGT) was noted in $5.2 \%$ of the participants who were not known to have IGT in the survey. Abdominal obesity and general obesity, which were defined as a waist circumference of more than $90 \mathrm{~cm}$ and a body mass index of $\geqslant 30$, respectively, were noted in $7.3 \%$ and $10.0 \%$ of the male respondents, respectively. The lifestyle risks related to cardiovascular disease were more prevalent than hypertension. The prevalence of current adult male smokers was $46.6 \%$, and the prevalence of physical inactivity was $35.3 \%$. In addition to the NHMS III, there were 
other smaller community studies that compared cardiovascular risk between urban and rural settings (Table 1). ${ }^{24-30}$ Although the prevalence of hypertension and hypercholesterolaemia in men was similar between urban and rural settings, the prevalence of obesity and diabetes was at least two times higher in urban settings. In contrast, smoking was more common in rural settings (Table 1). The prevalence of hypercholesterolaemia in local and regional studies was higher than that reported in the NHMS III because the men in the smaller studies were older. Nevertheless, the prevalence of all cardiovascular risk factors was high. Except for smoking, the prevalence of cardiovascular risk factors increased with age. ${ }^{18}$

\section{Injuries}

In the Malaysian Burden of Disease and Injuries Study 2000, injuries contributed to $16 \%$ of total DALYs in males. ${ }^{22}$ This was considerably higher than that of females, in whom injuries contributed to $6 \%$ of total DALYs. ${ }^{22}$ The types of injuries included road traffic injuries and injuries from occupational and other social activities. In males, road traffic accidents accounted for approximately $62 \%$ of the total burden of injuries. The DALY due to road traffic accidents was approximately five times higher in males than in females. ${ }^{22}$ For non-fatal unintentional injuries within the last year, the NHMS 2006 reported an overall incidence of $16.2 \%$. Males, compared to females, accounted for the majority of the injuries sustained in schools $(7.0 \%$ versus $6.0 \%)$, at work ( $4.8 \%$ versus $3.1 \%)$, on the road $(4.4 \%$ versus $2.5 \%)$ and during recreational activities $(1.7 \%$ versus $0.7 \%)$ but not injuries sustained at home $(6.5 \%$ versus $6.8 \%)$.

\section{Communicable diseases}

Although communicable diseases may not be the most important disease burden in men, they nonetheless contributed to $10.1 \%$ of the total DALYs compared to $8.1 \%$ in women. ${ }^{22}$ The majority of the burden in men $(62 \%)$ is due to septicaemia, followed by lower respiratory infections and HIV. The majority of septicaemia occurred in old age. For most infectious diseases, men have higher DALYs compared to women, particularly for tuberculosis and HIV infection (Figure 3). ${ }^{22}$

\section{Psychological health}

Based on the Malaysian Burden of Disease and Injury study 2000, mental disorders accounted for $8 \%$ of the total DALYs in men. ${ }^{22} \mathrm{~A}$ DALY is a better indicator of the burden of mental disorders because only $3 \%$ of the burden is due to mortality. Overall, major depression accounted for $45 \%$ of the burden of mental disorders. Alcohol and drug dependence occurred predominantly in men, whereas anxiety and depression were more common in women (Figure 4). Intentional injuries accounted for $1.7 \%$ of DALYs for the total population. Up to $98 \%$ of the burden from intentional injuries was due

Table 1 Prevalence of cardiovascular risk factors in urban and rural settings

\begin{tabular}{lcc}
\hline \multirow{2}{*}{ Cardiovascular risk factors } & \multicolumn{2}{c}{ Prevalence in men } \\
\cline { 2 - 3 } & Urban settings $^{24}$ & Rural settings \\
\hline Hypercholesterolaemia & 70.1 & 73.0 (Ref. 25) \\
$\quad\left(\mathrm{TC}>5.2 \mathrm{mmol}^{-1}\right.$ ) & & \\
Obesity (BMI $>25)$ & 65.8 & $5.7-38.7$ (Refs. 25-27) \\
Hypertension & 30.2 & 12.2 (Ref. 28)-29.8 (Ref. 25) \\
Diabetes & 21.4 & 4.7 (Ref. 25)-10.5 (Ref. 30) \\
Smoking & 19.1 & 52.2 (Ref. 25)-52.8 (Ref. 29) \\
\hline
\end{tabular}

Abbreviations: BMI, body mass index; TC, total cholesterol.

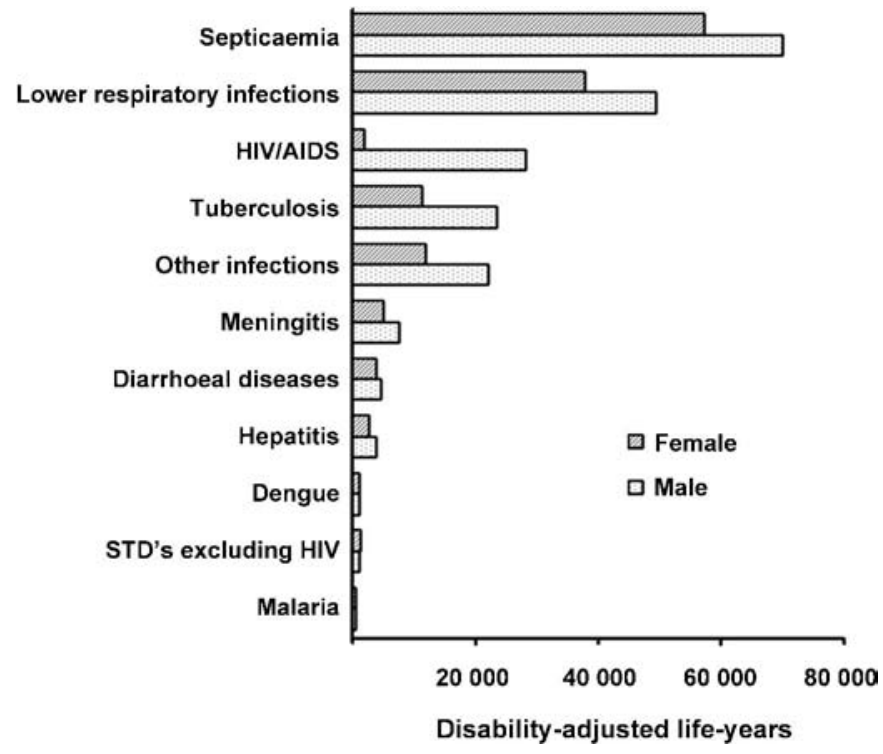

Figure 3 The burden of infectious disease by sex in Malaysia in 2000. ${ }^{22}$ Adapted with permission.

to mortality from the injuries. Self-inflicted injuries (suicide) and violence (including homicide) were the main causes of intentional injuries. For both causes, the DALYs for men were two to three times higher than those for women (Figure 4).

In the more recent 2006 NHMS III, the overall prevalence of psychiatric morbidity, as measured by the General Health Questionnaire (GHQ-28), was $11.2 \%$ (men: $10.4 \%$; women: $12.1 \%$ ). The overall prevalence of acute suicidal ideation was $6.4 \%$, and the prevalence of chronic suicidal ideation was $26 \%$. Among those with acute suicidal ideation, the prevalence in men was $5.9 \%$, whereas that in women was $6.7 \%$. As for chronic suicidal ideation, the prevalence in women was slightly higher $(25.8 \%)$ than in men $(25.0 \%)$. The overall prevalence of acute insomnia was $14 \%$ (men: $13.1 \%$; women: $15.1 \%$ ). In terms of chronic insomnia, the overall prevalence was $47.8 \%$ (men: $45.5 \%$ ' women: $50.1 \%$ ). In addition to the above data, other subscales measured by the GHQ-28 include depression, anxiety and social dysfunction. In terms of the depression subscale, females had a significantly higher depression score (mean of 1.2; 95\% confidence interval (CI): $1.2-1.3$ ) compared to males (mean of $1.1 ; 95 \%$ CI: 1.0-1.1). Similarly,

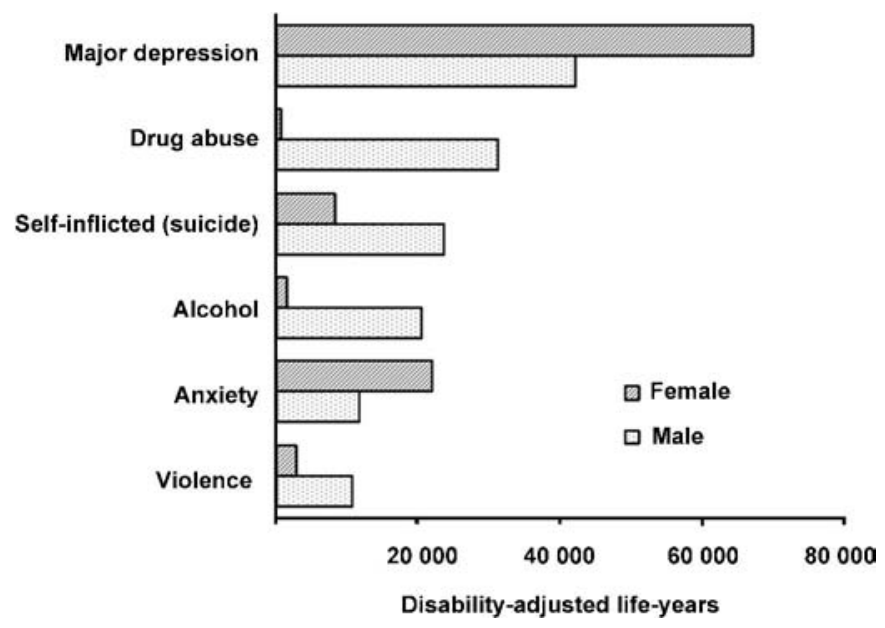

Figure 4 The burden of mental disorders by sex in Malaysia in $2000 .^{22}$ 
females had a significantly higher anxiety subscale score at a mean of 3.3 (95\% CI: 3.2-3.4) compared to males, with a mean of 3.0 (95\% CI: 2.9-3.1). However, no gender differences were observed in the social dysfunction subscale scores.

In summary, the proportion of men who suffer from mental disorders was significantly lower than that of women. However, men contributed to the majority of deaths caused by suicide and the DALYs due to drug and alcohol dependence.

\section{Cancer}

In the Malaysian Burden of Disease and Injuries Study 2000, cancer was responsible for $6 \%$ of the total DALYs in men. ${ }^{22}$ According to the national cancer registry, over a period of 3 years from 2003 to 2005, the age-standardized male cancer incidence was 136.9 per 100000 population compared to the female incidence of 156.9 per 100000 population in Peninsular Malaysia. ${ }^{31}$ However, excluding sex-specific cancer types, the incidence rates of common cancers were higher in men than in women (Figure 5). ${ }^{20}$ The most common cancer in males was colorectal cancer, which accounted for $14.5 \%$ of the total incidence of cancer. This was followed by lung cancer (12.2\%), nasopharyngeal cancer $(7.8 \%$; mainly among Chinese), prostate cancer $(7.3 \%)$ and leukaemia (6.5\%). The incidence rates were 20.9 per 100000 population for colorectal cancer (1.2 times higher than that in females), 20.9 per 100000 population for lung cancer (3 times higher than that in females), 9.2 per 100000 population for nasopharyngeal cancer ( 3 times higher than that in females) and 7.0 per 100000 population for leukaemia (1.5 times higher than that in females). The age-standardized incidence of prostate cancer was 12.0 per 100000 population in 2005, which was higher than the incidence of 10.3 per 100000 population in 2003. ${ }^{32}$ Testicular and penile cancers were relatively uncommon, and the age-standardized rates were only 1.1 and 0.3 per 100000 population, respectively. The epidemiology of cancers is changing. In 1985, the three most common sites of male cancers in East Malaysia were lymph nodes, nasopharynx and skin. ${ }^{33}$ Similarly, in 1994, a regional survey and a local registry in Peninsular Malaysia documented that the five most common male cancers were lung, nasopharynx, stomach, urinary bladder and rectum. ${ }^{34}$ Colorectal and prostate cancer was not in the list of the five most

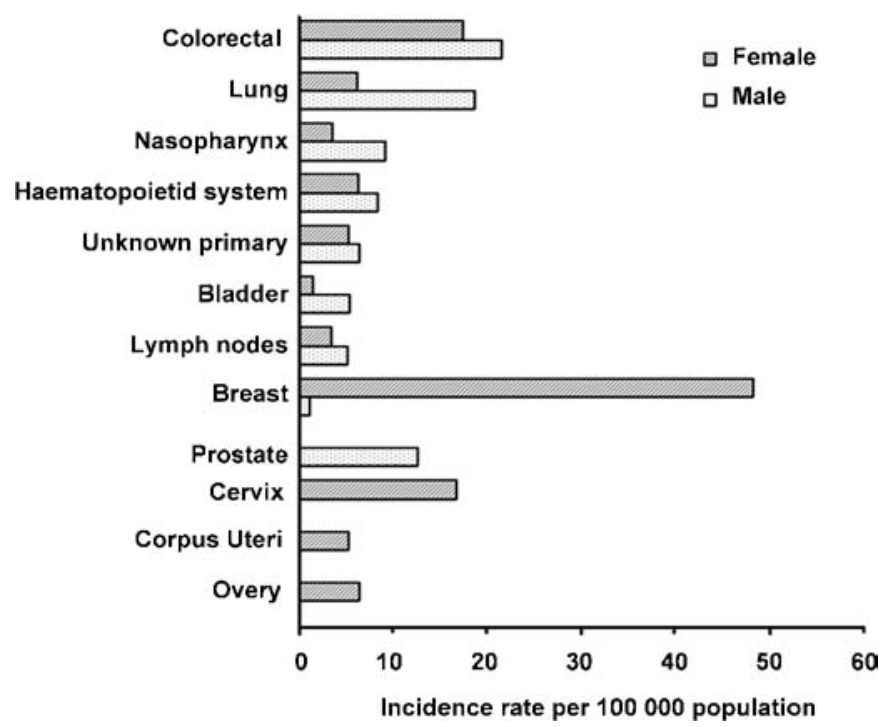

Figure 5 Age-standardized incidence of cancer per 100000 population by sex in Peninsular Malaysia, 2003-2005. ${ }^{31}$ common cancers. However, a more recent audit of cancer cases treated at a tertiary referral centre in 2008 found a fourfold increase in the numbers of colorectal cancer treated at the hospital since 2000. The number of prostate cancer treated also increased from fewer than four cases treated in 2000 to 25 cases in $2007 .^{35}$

\section{Prostate and male LUTS}

To date, there has been no large-scale national study on prostate disorders in Malaysia. However, there have been several local studies on the prevalence of prostate disorders. Two studies involved men who were randomly selected from the community: the Subang men's health study ${ }^{17,24}$ and the Penang study. ${ }^{36}$ In the study on urban men older than 40 years from Subang, the prevalence of a self-reported 'prostate problem' in 2003 was $11.4 \%$. However, the prevalence of LUTS in the same study, as defined by the International Prostate Symptoms Score scale of $>8$, was $29.0 \% .^{17,24}$ In 2006, the Penang study, which included both urban and rural respondents of the same age group, revealed that the prevalence of LUTS with the same definition was $6.2 \%$. Two other community studies that used convenient sampling methods documented prevalences of $34 \%,{ }^{37}$ and $58.5 \% .^{38}$ The higher of these two rates is most likely an overestimation because they recruited men above the age of 50 years compared to 40 years in the two former community surveys. In an attempt to assess public awareness of benign prostate hypertrophy, Zainal et al. ${ }^{39}$ recruited 200 men aged 40 years and above, who were admitted to a district hospital in 2005 to assess their level of awareness; $90 \%$ of the respondents were noted to be unaware of their condition.

Prostatitis was another prostate disorder in which the epidemiology of the disease was studied. In a survey of randomly selected men aged 20-50 years from Penang, the prevalence of chronic prostatitis was $8.7 \%{ }^{40}$ Prostatitis was believed to be under-diagnosed because less than $1 \%$ of the men treated in primary care settings in the same location was diagnosed with chronic prostatitis. ${ }^{41}$

\section{Male sexual health}

The Global Study of Sexual Attitudes and Behaviours, ${ }^{42}$ which surveyed men aged 40 years and above, showed that $91.1 \%$ of Malaysian men had been sexually active within the last 12 months. ED is the most commonly studied male sexual health condition in Malaysia. A total of five large-scale community surveys on the epidemiology of ED were identified. One of the studies was part of a multinational study on sexual health. ${ }^{42}$ The reported prevalence of erectile dysfunction ranged from $17.2 \%{ }^{42}$ to $53.6 \% .{ }^{13,24,36,43}$ The lowest prevalence rate was reported by Nicolosi et al. ${ }^{13}$ in a multinational study; however, that study had a low response rate of $16 \%$ in Malaysia. The findings from the other three local studies were more consistent and showed that the prevalence of moderate to severe ED (defined as an IIEF-5 score $<17$ ) ranged from 37.3 to $53.6 \% .^{24,36,43}$ The prevalence of ED increased with age. In the 40 - to 49 -year age group, the prevalence was $4.8 \%$, followed by $22.2,40.3$ and $79.5 \%$ in the 50 - to $59-, 60$ - to 69 - and $\geqslant 70$-year age groups, respectively. ${ }^{36}$ There was no association between ED and ethnicity (Malay, Chinese and Indian). ${ }^{24,43}$ However, there were significant associations between ED and obesity, ${ }^{24,36}$ smoking, ${ }^{36}$ diabetes, ${ }^{36,43}$ hypertension ${ }^{36,43}$ and depression. ${ }^{24}$

Premature ejaculation (PE) is another male sexual health condition that has been studied. ${ }^{43}$ In a study on PE that involved men older than 20 years in an urban setting, the prevalence was $22.3 \% .{ }^{43}$ The study used a self-reported intravaginal ejaculation latency time of $\leqslant 2 \mathrm{~min}$ as the definition of PE. Its prevalence was found to be the highest (17\%) among men aged $20-29$ years, followed by $13 \%, 9 \% 1 \%$ and $0 \%$ for the 
30- to 39-, 40- to 49-, 50- to 59- and $\geqslant 60$-year age groups, respectively. ${ }^{43}$ Approximately $60 \%$ of men with anxiety and depression who scored $>11$ points on the Depression Anxiety Stress Scale had PE. The prevalence of PE was four to five times higher among men with anxiety and depression compared to men without these disorders. ${ }^{43}$

\section{DISCUSSION}

\section{Men's health status in Malaysia}

The findings of this review confirmed the state of health among Malaysian men, which is worrisome for several reasons. First, the life expectancy at birth is lower in men compared to women in Malaysia. This finding is similar to the pattern observed worldwide; the life span of men, on average, is 3.9 years shorter than that of women. ${ }^{3,4}$ The death rates were also higher in men across all age groups as observed in other regions in the world. ${ }^{19}$

Second, the prevalence of disease and modifiable risk factors contributing to the cause of death is higher among men. These disorders and their associated risk factors are preventable or amenable to early interventions. The main causes of death are cardiovascular disease and injuries (including traffic accidents). Cancer-related death is also becoming a major health problem among Malaysian men, with an increasing incidence of colorectal, lung, laryngeal and prostate cancers. ${ }^{44}$ Risk factors, such as smoking, hypertension, hypercholesterolaemia, diabetes and risk-taking behaviour, can be managed using effective interventions (for example, death from injuries could be reduced with modifications of risk-taking behaviour). In addition to smoking, the prevalence of other cardiovascular risk factors is increasing at an alarming rate. The prevalence of hypertension in men aged 30 years and above has increased from $33 \%$ in 1996 to $42 \%$ in 2006; the prevalence of diabetes mellitus has increased from 8 to $15 \%$, high cholesterol from 20 to $26 \%$ and obesity from 3 to $10 \%$ over the same period. On the other hand, smoking decreased minimally from $49.7 \%$ in 1996 to $48.8 \%$ in $2006{ }^{18}$

Third, many of these risk factors remain undetected, and early interventions are therefore not performed. In the NHMS 2006, the rates of newly diagnosed diabetes and IGT in male participants (5.1 and $5.2 \%$, respectively) were significantly higher than those for female participants, who showed rates of only 4.1 and $3.5 \%$, respectively. ${ }^{18}$ This is most likely because women are typically screened during their antenatal period, which leads to the identification of diabetes and IGT. In contrast, men are not privy to such screening opportunities. In addition, the NHMS 2006 showed that many men were also unaware of their hypertension and hypercholesterolaemia status. Similar findings were observed in a survey of men in an urban setting in Malaysia. ${ }^{45}$ These silent risk factors and disorders can only be diagnosed and treated if men attend health checks. Furthermore, women have a higher self-reported prevalence of mental disorders compared to men, but men have higher death rates due to self-inflicted injuries. This suggests that men may not recognize or report their mental problems but may rather allow their illness to progress before seeking help. Therefore, shorter life expectancy and the high prevalence of modifiable health risks among men will continue to be important health issues as long as they remain undetected or unreported. The problems will escalate as the country develops mainly because of the increasingly sedentary lifestyles and the rapidly aging population. ${ }^{46}$

Male urological conditions and sexual health problems are also prevalent. The high prevalence of LUTS in Malaysia is consistent with the findings in many other countries, and it increases with age from 13 to $56 \%$ for the age groups $40-49$ years to $>70$ years respectively. ${ }^{47-49}$ The high prevalence of ED in Malaysia is also consistent with rates reported across the world; prevalence of ED ranges from 15 to $54 \%$ for men above 40 years of age. ${ }^{11,42}$ Despite the high prevalence and substantial impact of LUTS and ED on men's quality of life, ${ }^{9}$ many men still do not seek treatment. This review noted that the rates of selfreported LUTS and ED among men in the community were much lower compared to those of men diagnosed objectively in the surveys. The prevalence of LUTS based on the self-administered International Prostate Symptoms Score questionnaire was also lower in surveys in rural settings, ${ }^{36}$ which reflects the lower level of awareness of LUTS; ${ }^{39}$ this further supports the fact that a significant number of men with LUTS are undiagnosed and are therefore deprived of effective treatment. Under-reporting of ED and LUTS is not unique to the Malaysian setting; studies from $\operatorname{Japan}^{50}$ and the United Kingdom ${ }^{51}$ and the global sexual health survey ${ }^{52}$ consistently found under-reporting of LUTS and ED.

$\mathrm{PE}$ is another common sexual health problem that is underresearched in Malaysia, and to date, there has only been one published study on PE in Malaysia. ${ }^{43}$ The prevalence of $\mathrm{PE}$ in various large-scale studies is estimated to be $22-38 \%$ across all age groups of men. ${ }^{52,53} \mathrm{PE}$ is increasingly recognized as a major sexual health problem for men because of its negative impact on quality of life. Furthermore, ED is associated with an increased risk of future cardiovascular events. ${ }^{10}$ Therefore, screening for ED is warranted because it acts as the sentinel marker for cardiovascular disease. ${ }^{11}$

The male mortality and morbidity patterns in Malaysia are similar to those of East Asian countries and other developed countries ${ }^{54}$ (Table 2). Although communicable diseases are still important, the major concern is the increasing incidence of cardiovascular disease and cancer. In Malaysia, cardiovascular disease is the most common natural cause of death. However, as health services have improved, the cardiovascular death rate should decrease. In more developed countries in Asia, such as South Korea and Japan, cancer death rate is the highest among the major causes of death and exceeds the cardiovascular death rate ${ }^{55}$ (Table 2). Notably, in many Western countries, there is a decreasing trend in cardiovascular death rates. ${ }^{56}$ Therefore, increasing death rates for cardiovascular disease are not inevitable, and effective measures are available to address the problem.

\section{Gaps in research on men's health issues in Malaysia}

To date, the epidemiological data have demonstrated that the burden of illness in Malaysian men is significant and requires urgent attention. This burden is no different from the data documented worldwide. Exploratory research is needed to identify the reasons for poor health status in men. In Malaysia, we need good-quality exploratory research in various areas to guide the development of effective interventions to improve this health status of men. Such research areas include the following: (i) men's health-seeking behaviour and factors that influence it; (ii) health-care utilisation by men and whether this could be a factor in the poor health status of men; (iii) health needs assessment of men from the perspective of men because they are the main stakeholders in their own health; and (iv) whether health service delivery meets the expectations and needs of men.

In one study that identified factors influencing health-seeking behaviour in men with sexual problems, it was found that the major factor that motivates men to seek help for ED was their wives' dissatisfaction with the sexual relationship. ${ }^{57}$ In another study on general men's health issues, ${ }^{58}$ the important motivators of healthy lifestyles were positive family values, triggers from acute illnesses and the push factors from wives and friends. On the other hand, the important barriers to adopting healthy lifestyles were lack of time to exercise and high health-care costs; for smokers, the major barrier was the enjoyment of the companionship of their fellow smokers. ${ }^{58}$ Other barriers identified 
Table 2 Comparison of men's mortality and morbidity statistics between selected Asian countries ${ }^{54,55}$

\begin{tabular}{|c|c|c|c|c|c|c|c|c|c|c|}
\hline \multirow{2}{*}{$\begin{array}{l}\text { Selected } \\
\text { Asian } \\
\text { countries }\end{array}$} & \multirow{2}{*}{$\begin{array}{c}\text { Life } \\
\text { expectancy } \\
\text { at birth }\end{array}$} & \multirow[b]{2}{*}{$H A L E$} & \multicolumn{5}{|c|}{ Age-standardized death rates per 100000 males } & \multicolumn{3}{|c|}{ Prevalence of lifestyle risk factors } \\
\hline & & & $\begin{array}{c}\text { Cardio-vascular } \\
\text { diseases }\end{array}$ & $\begin{array}{l}\text { Malignant } \\
\text { neoplasm }\end{array}$ & $\begin{array}{l}\text { Infectious } \\
\text { diseases }\end{array}$ & $\begin{array}{c}\text { Self-inflicted } \\
\text { injuries }\end{array}$ & $\begin{array}{c}\text { Un-intentional } \\
\text { injuries }^{a}\end{array}$ & $\begin{array}{c}\text { Adult } \\
\text { obesity (\%) }\end{array}$ & $\begin{array}{c}\text { Alcohol } \\
\text { consumption }^{b}\end{array}$ & $\begin{array}{c}\text { Adult } \\
\text { smoking (\%) }\end{array}$ \\
\hline Japan & 79 & 73 & 129.5 & 167.1 & 10.6 & 29.3 & 27.2 & 21.1 & 0.4 & 42.2 \\
\hline Singapore & 79 & 71 & 191.9 & 141.3 & 11.8 & 13.6 & 21.7 & 6.7 & 2.1 & 36.3 \\
\hline $\begin{array}{l}\text { Republic of } \\
\text { Korea }\end{array}$ & 76 & 68 & 190.0 & 243.6 & 21.6 & 39.7 & 57.6 & 2.8 & 11.8 & 53.3 \\
\hline China & 72 & 65 & 297.8 & 183.1 & 46.9 & 16.0 & 70.2 & 2.4 & 4.4 & 59.5 \\
\hline Malaysia & 71 & 62 & 287.3 & 159.3 & 112.5 & 11.2 & 49.6 & 13.9 & 0.5 & 52.6 \\
\hline Vietnam & 70 & 62 & 331.4 & 138.3 & 131.4 & 14.2 & 60.9 & - & 6.9 & 31.6 \\
\hline Indonesia & 66 & 60 & 367.7 & 139.2 & 142.8 & 13.7 & 149.5 & 1.1 & $<0.1$ & 61.7 \\
\hline Thailand & 66 & 59 & 162.8 & 156.7 & 233.0 & 14.7 & 80.0 & 3.3 & 6.5 & 43.1 \\
\hline India & 63 & 56 & 409.7 & 105.8 & 198.5 & 22.7 & 101.8 & 1.3 & 0.6 & 33.2 \\
\hline Pakistan & 63 & 56 & 436.1 & 107.1 & 199.1 & 12.8 & 66.1 & - & $<0.1$ & 35.4 \\
\hline Myanmar & 53 & 48 & 472.9 & 123.0 & 321.4 & 11.9 & 68.7 & - & 0.1 & 42.6 \\
\hline Afghanistan & 40 & 36 & 820.5 & 194.2 & 448.3 & 4.9 & 99.1 & - & $<0.1$ & - \\
\hline
\end{tabular}

Abbreviation: HALE, Healthy life expectancy.

${ }^{a}$ Road traffic accidents, poisonings, falls, fires and drownings.

${ }^{\mathrm{b}}$ Litres of pure alcohol/person/year.

included the lack of accessible men's health information and perception of invulnerability to illness. These studies highlighted the significant influence of men's family and friends on their health behaviour. It also demonstrated that men require triggers to adopt healthy behaviour. These findings are consistent with the results from studies in Western countries, which have shown that men's health behaviour is greatly influenced by the societal expectations of men and the need to uphold the masculine image. ${ }^{7,59-61}$ Men seeking help or adopting healthy lifestyles are perceived as demonstrating weakness, and these behaviours represent a threat to their masculinity. ${ }^{59,62,63}$ They would accept health-promoting activities only if they are 'asked to'. When men are asked directly whether they care about their health, many men would say yes without hesitation. ${ }^{58,64}$ However, despite the advances in men's health psychology, there is still a lack of evidence in many areas mentioned above, such as men's unmet needs and how they would like to be involved in health care. Evidence-based strategies that are sensitive to men's needs are also lacking. ${ }^{65}$ Strategies for effectively communicating health messages to men and engaging them in health care are needed. These strategies will include effective public health education, health-care delivery, cultivating healthy lifestyles and imparting health messages to men.

\section{Challenges ahead}

There are many challenges ahead in promoting and improving men's health in Malaysia. Malaysia is a rapidly developing country with an increasing standard of living. Life expectancy at birth is increasing, and the population is aging. Therefore, men's health problems are escalating at an alarming rate. The problems are compounded by the lack of emphasis on male-sensitive health service delivery. ${ }^{17}$ Empirical data on the root causes of men's health problems are lacking. Theoretical concepts and the understanding of men's health derived from Western studies may not be relevant or applicable to solving men's health problems in the local context, because Malaysia is a multi-ethnic country with diverse cultures. Galdas et al. ${ }^{66}$ have shown that health-seeking behaviour for chest pain in South Asian men was different from that of Caucasian men.

Currently, there is no health policy that promotes men's health activities in Malaysia. ${ }^{17}$ Health policy is important to serve as a framework to advocate and promote men's health. It is hoped that more resources and concerted efforts will be directed towards promoting men's health if such policy is made available. Although certain activities have been targeted at health issues related to men at the national, regional or local levels, such as health campaigns for non-communicable diseases, healthy lifestyle, smoking cessation, occupational health, injury prevention and family health, ${ }^{17}$ they do not cater specifically to men. Important factors that underlie men's specific health problems, such as men's health-seeking behaviour and myths about men's health, are not being addressed. Therefore, without a men's health policy, health campaigns for men will remain fragmented, and health-care delivery will not be male gender sensitive.

Myths about men being ignorant about their health still prevail within Malaysian society, but they are not substantiated by evidence. It is easy to adopt an accusatory attitude towards men who refuse health promotional activities, but this is not helpful in resolving men's health issues. A qualitative study of urban men older than 40 years in Malaysia found that men have the utmost desire to stay healthy. ${ }^{58}$ However, they found many obstacles in seeking health promotional services, such as time constraints, high cost, lack of information and lack health-care worker competence. ${ }^{58}$ Moreover, the health services are not male-friendly. ${ }^{67-69}$ Securing a job and having lots of money are seen as symbols of manliness. ${ }^{70}$ Therefore, long hours of waiting in consultation rooms and expensive health promotional activities could potentially deter men from optimally utilizing health services. An approach to targeting the needs of patients has already been successfully used in women and child health services, where mobile clinics to most remote parts of Malaysia are made available. ${ }^{16}$ The challenge is to reposition the system to acknowledge the health-care needs of men.

Perhaps the greatest challenge to men's health promotion is the undoing of the negative influence of society on men; that is, men's need to uphold their masculine image. The image of a 'real man' is a man who is in control in his life. ${ }^{70}$ Taking up health promotional activities and seeking help for one's health problems are seen as giving away that control. Health-care providers also expect men to be independent, to take charge of their health and to adapt themselves to the present health-care system. 'Men should present early rather than late for their illness' is a common remark. Together with the myths about men's health, society does not seem to provide a supportive environment for men to utilize health promotional activities. 


\section{CONCLUSIONS}

Recognizing and addressing men's health issues is long overdue in Malaysia. Although this review focuses on the Malaysian setting, it should be applicable to other Asian countries who share many cultural values with Malaysia. It is certainly not a new problem, but one that has only surfaced through careful study of male mortality and morbidity patterns while acknowledging the impact of gender on health. In many parts of the world, men's health has drawn interest via promotion of male sexual and urological health. However, such efforts have been moved to take a more holistic approach and to address the underpinnings of men's health issues through men's health psychology. In Malaysia, recognizing men's health issues is in its infancy, with many gaps in our knowledge and challenges to be addressed. The needs assessment from various stakeholders in the men's health area should include men in the community, health-care providers and policy makers. The Malaysian society must adopt a more positive attitude towards men's health. Health promotion has to be seen as an important agenda during every encounter with a male patient in a clinic. Service providers must cater to men's needs rather than instructing them to adapt to the present health-care system. A more gendersensitive approach, which has been advocated for women's health, must be applied to tackle the growing men's health issues in Malaysia.

\section{COMPETING FINANCIAL INTERESTS}

The authors declare no competing financial interests.

\section{ACKNOWLEDGMENTS}

We thank Masni-Azian Akiah for helping with the formatting of the manuscript.

1 Baker $P$. The international men's health movement. BMJ 2001; 323: 1014-5.

2 Wilkins D, Savoye E, editors. Men's Health Around the World: A Review of Policy and Progress Across 11 Countries. Brussels: European Men's Health Forum, 2009.

3 Mathers CD, Sadana R, Salomon JA, Murray CJ, Lopez AD. Healthy life expectancy in 191 countries, 1999. Lancet 2001; 357: 1685-91.

4 Gollogly L, editor. World Health Statistics 2009. Geneva: World Health Organisation Press, 2009.

5 Macdonald JJ. Shifting paradigms: a social-determinants approach to solving problems in men's health policy and practice. Med J Aust 2006; 185: 456-8.

6 Kraemer S. The fragile male. BMJ 2000; 321: 1609-12.

7 Broom A, Tovey P. Men's Health: Body, Identity and Social Context. Chichester: WileyBlackwell, 2009.

8 Courtenay W. Key determinants of the health and well-being of men and boys. Int J Mens Health 2003; 2: 1-30.

9 Low WY, Tong SF, Tan HM. Erectile dysfunction, premature ejaculation and hypogonadism and men's quality of life: an Asian perspective. J Mens Health 2008; 5: $282-88$

10 Tikkanen M, Jackson G, Tammela T, Assmann G, Palomäki A et al. Erectile dysfunction as a risk factor for coronary heart disease: implications for prevention. Int J Clin Pract 2007; 61: 265-8

11 Selvin E, Burnett A, Platz E. Prevalence and risk factors for erectile dysfunction in the US. Am J Med 2007; 120: 151-7.

12 Ng CJ, Tan HM, Low WY. Masculinity and help-seeking behaviour in Asian men: findings from the Asian Men's Attitudes to Life Events and Sexuality (MALES) study. J Sex Med 2009; 6(Suppl 2): 78.

13 Nicolosi A, Glasser DB, Kim SC, Marumo K, Laumann EO et al. Sexual behaviour and dysfunction and help-seeking patterns in adults aged 40-80 years in the urban population of Asian countries. BJU Int 2005; 95: 609-14.

14 Tan HM, Low WY, Ng CJ, Chen KK, Sugita M et al. Prevalence and correlates of erectile dysfunction (ED) and treatment seeking for ED in Asian men: the Asian Men's Attitudes to Life Events and Sexuality (MALES) study. J Sex Med 2007; 4: 1582-92.

15 Department of Statistics Malaysia. Life Expectancy at Birth. Key Statistics. Putrajaya: Department of Statistics Malaysia, 2009.

16 Pathmanathan I, Dhairiam S. Malaysia: moving from infectious to chronic diseases. In: Tarimo E, Creese A, editors. Achieving Health for All by the Year 2000: Midway Reports of Country Experiences. Geneva: World Health Organization, 1990.

17 Tan HM, Tong SF, Low WY, Ng CJ. Men's health in Malaysia. In: Wilkins D, Savoye E, editors. Men's Health Around The World: A Review of Policy and Progress Across 11 Countries. Brussels: European Men's Health Forum, 2009, pp39-44.

18 Institute for Public Health (IPH). The Third National Health and Morbidity Survey (NHMS III) 2006. Kuala Lumpur: Institute for Public Health, 2008.
19 WHO. The Global Burden of Disease: 2004 Update. Geneva: World Health Organisation Press, 2008.

20 Department of Statistics Malaysia. Statistics on Causes of Death in Malaysia 2006. 2009 edn. Putrajaya: Department of Statistics Malaysia, 2009.

21 Volp U. Hypertension, a health problem in Malasia. Bull Public Health Soc 1975; 9: 59-65.

22 Yussof AF, Mustafa AN, Kaur G, Omar MA, Vos T et al. Malaysian Burden of Disease and Injury Study. Kuala Lumpur: Institute of Public Health, Ministry of Health Malaysia, 2004

23 Ministry of Health $(\mathrm{MOH})$. The Third National Health and Morbidities Survey. Kuala Lumpur: Ministry of Health Malaysia, 2006.

24 Khoo EM, Tan HM, Low WY. Erectile dysfunction and comorbidities in aging men: an urban cross-sectional study in Malaysia. J Sex Med 2008; 5: 2925-34.

25 Nawawi HM, Nor IM, Noor IM, Karim NA, Arshad F et al. Current status of coronary risk factors among rural Malays in Malaysia. J Cardiovasc Risk 2002; 9: 17-23.

26 Mohamad WB, Mokhtar N, Mafauzy M, Mustaffa BE, Musalmah M. Prevalance of obesity and overweight in northeastern peninsular Malaysia and their relationship with cardiovascular risk factors. Southeast Asian J Trop Med Public Health 1996; 27: 339-42.

27 Nazri SM, Imran MK, Ismail IM, Faris AA. Prevalence of overweight and self-reported chronic diseases among residents in Pulau Kundur, Kelantan, Malaysia. Southeast Asian J Trop Med Public Health 2008; 39: 162-7.

28 Mafauzy M, Mokhtar N, Wan Mohamad WB. Hypertension and associated cardiovascular risk factors in Kelantan. Med J Malaysia 2003; 58: 556-64.

29 Rampal L, Narasimman S. A community based study on the prevalence and factors affecting smoking in Kampong Jenderam Hilir, Sepang, Selangor. Med J Malaysia 2003; 58: 54-61.

30 Mafauzy M, Mokhtar N, Mohamad WB, Musalmah M. Diabetes mellitus and associated cardiovascular risk factors in north-east Malaysia. Asia Pac J Public Health 1999; 11: 16-9.

31 Lim GCC, Rampal S, Yahaya H. Cancer Incidence in Peninsular Malaysia, 2003-2005 Kuala Lumpur: National Cancer Registry, 2008.

32 Lim G, Halimah Y. Second Report of the National Cancer Registry Cancer Incidence in Malaysia 2003. Kuala Lumpur: National Cancer Registry, Ministry of Health Malaysia, 2004.

33 Dawie Usop AK. Epidemiology of cancer in Sarawak, East Malaysia. Southeast Asian J Trop Med Public Health 1985; 16: 584-90.

34 Lim G. Overview of cancer in Malaysia. Jpn J Clin Oncol 2002; 32: 37-42.

35 Othman NH, Nor ZM, Biswal BM. Is Kelantan joining the global cancer epidemic? experience from hospital Universiti Sains Malaysia; 1987-2007. Asian Pac J Cancer Prev 2008; 9: 473-8.

36 Mariappan P, Chong WL. Prevalence and correlations of lower urinary tract symptoms, erectile dysfunction and incontinence in men from a multiethnic Asian population: results of a regional population-based survey and comparison with industrialized nations. BJU Int 2006; 98: 1264-8.

37 Li MK, Garcia LA, Rosen R. Lower urinary tract symptoms and male sexual dysfunction in Asia: a survey of ageing men from five Asian countries. BJU Int 2005; 96: 133954.

38 Teh GC, Sahabudin RM, Lim TC, Chong WL, Woo S et al. Prevalence of symptomatic BPE among Malaysian men aged 50 and above attending screening during prostate health awareness campaign. Med J Malaysia 2001; 56: 186-95.

39 Zainal SB, Quek KF, Biswajit C. Awareness of prostatism among male patients in Teluk Intan Hospital. Med J Malaysia 2005; 60: 540-7.

40 Cheah PY, Liong ML, Yuen KH, Teh CL, Khor T et al. Chronic prostatitis: symptom survey with follow-up clinical evaluation. Urology 2003; 61: 60-64.

41 Lee SWH, Liong ML, Yuen KH, Leong WS, Khan N et al. Prostatitis-like symptoms: diagnosis and management in a Malaysian primary care population. Urol Int 2009; 82: 32-7.

42 Nicolosi A, Moreira ED Jr, Shirai M, Bin Mohd Tambi MI, Glasser DB. Epidemiology of erectile dysfunction in four countries: cross-national study of the prevalence and correlates of erectile dysfunction. Urology 2003; 61: 201-6.

43 Quek KF, Sallam AA, Ng CH, Chua CB. Prevalence of sexual problems and its association with social, psychological and physical factors among men in a Malaysian population: a cross-sectional study. J Sex Med 2008; 5: 70-6.

$44 \mathrm{Pu}$ YS, Chiang HS, Lin CC, Huang CY, Huang KH et al. Changing trends of prostate cancer in Asia. Aging Male 2004; 7: 120-32.

$45 \mathrm{Ng} \mathrm{CJ}$, Tan HM, Khoo EM, Low WY. Under-detection and under treatment of common men's health problems. Asian J Androl 2007; 9: 418

46 Department of Statistics Malaysia. Year Book of Statistic 2008. Putrajaya: Department of Statistics, Malaysia, 2009.

47 Chute CG, Panser LA, Girman CJ, Oesterling JE, Guess HA et al. The prevalence of prostatism: a population-based survey of urinary symptoms. J Urol 1993; 150: 85-9.

48 Homma Y, Kawabe K, Tsukamoto T, Yamanaka H, Okada K et al. Epidemiologic survey of lower urinary tract symptoms in Asia and Australia using the international prostate symptom score. [Erratum appears in Int J Urol 1997 Mar; 4(2): 232]. Int J Urol 1997; 4: 40-6.

49 Garraway WM, Collins GN, Lee RJ. High prevalence of benign prostatic hypertrophy in the community. Lancet 1991; 338: 469-71.

50 Homma Y, Yamaguchi O, Hayashi K, Neurogenic Bladder Society Committee. Epidemiologic survey of lower urinary tract symptoms in Japan. Urology 2006; 68 : 560-4.

51 Trueman P, Hood SC, Nayak US, Mrazek MF. Prevalence of lower urinary tract symptoms and self-reported diagnosed 'benign prostatic hyperplasia', and their 
effect on quality of life in a community-based survey of men in the UK. BJU Int 1999; 83: 410-5.

52 Moreira E, Brock G, Glasser D, Nicolosi A, Laumann E et al. Help-seeking behaviour for sexual problems: the global study of sexual attitudes and behaviors. Int J Clin Pract 2005; 59: 6-16.

53 McCarty EJ, Dinsmore WW. Premature ejaculation: treatment update. Int J STD AIDS 2010; $21: 77-81$.

54 World Health Organization. World Health Statistics 2010. Geneva: World Health Organization, 2010.

55 World Health Organization. Death and DALY estimates for 2004 by cause for WHO member states. Males, all ages. 2009 [Cited 24 August 2010.] Available from: http:// www.who.int/healthinfo/global_burden_disease/estimates_country/en/index.html

56 Kesteloot H, Sans S, Kromhout D. Dynamics of cardiovascular and all-cause mortality in Western and Eastern Europe between 1970 and 2000. Eur Heart J 2006; 27: $107-$ 1357.

57 Ng CJ, Low WY, Choo WY, Tan HM. Exploring the factors influencing health seeking behaviour of men with ED. Asian J Androl 2004; 6: 188.

58 Low WY, Tan HM, Tong SF, Ng CJ, Khoo EM et al. About Men's Health: Views from Mars and Venus. Kuala Lumpur: MSASAM, 2008.

59 Courtenay WH. Constructions of masculinity and their influence on men's well-being: a theory of gender and health. Soc Sci Med 2000; 50: 1385-401.

60 Galdas PM. Men, masculinity and help-seeking behaviour. In: Broom A, Tovey P, editors. Men's Health: Body, Identity and Social Context. Chichester: WileyBlackwell, 2009. pp63-82.
61 Schofield T, Connell RW, Walker L, Wood JF, Butland DL. Understanding men's health and illness: a gender-relations approach to policy, research, and practice. J Am Coll Health 2000; 48: 247-56.

62 Galdas PM, Cheater F, Marshall P, Galdas PM, Cheater F et al. Men and health helpseeking behaviour: literature review. J Adv Nurs 2005; 49: 616-23.

63 Addis ME, Mahalik JR. Men, masculinity, and the contexts of help seeking. Am Psychol 2003; 58: 5-14.

64 Robertson S. Understanding Men and Health: Masculinities, Identity and Well-being. Maidenhead, England: New York: McGraw Hill/Open University Press, 2007.

65 Robertson LM, Douglas F, Ludbrook A, Reid G, van Teijlingen E. What works with men? A systematic review of health promoting interventions targeting men. BMC Health Serv Res 2008; 8: 141.

66 Galdas P, Cheater F, Marshall P. What is the role of masculinity in white and South Asian men's decisions to seek medical help for cardiac chest pain? J Health Serv Res Policy 2007; 12: 223-9.

67 Banks I. New models for providing men with health care. J Mens Health Gend 2004; 1: 155-58.

68 White A, Fawkner HJ, Holmes M. Is there a case for differential treatment of young men and women? Med J Aust 2006; 185: 454-5.

69 Smith JA, Braunack-Mayer A, Wittert G. What do we know about men's help-seeking and health service use? Med J Aust 2006; 184: 81-3.

$70 \mathrm{Ng}$ CJ, Tan HM, Low WY. What do Asian men consider as important masculinity attributes? Findings from the Asian Men's Attitudes to Life Events and Sexuality (MALES) Study. J Mens Health 2008; 5: 350-5. 